\title{
SUCCESSFUL LEADERSHIP OF VIRTUAL TEAMS: CHALLENGES AND BEST PRACTICES
}

\author{
Corina Maria RUSU ${ }^{a *}$, Silviu Ilie S $\breve{A P L} \breve{A C A N}{ }^{b}$, Ramona $L I L E^{c}$ \\ ${ }^{a},{ }^{b},{ }^{c}$ Aurel Vlaicu University of Arad, Romania
}

DOI: $10.24818 / \mathrm{IMC} / 2020 / 04.06$

\begin{abstract}
Managing the activities of remote employees and teams is key in today's globalized world. Advances in communication technology have enabled virtual interaction to the extent that it has now become commonplace. However, lack of physical interaction and face-to-face contact can be a complicated experience for any communicator. Are the rules for remote employees or virtual teams different? Is managing a remote team different than managing a conventional office team? What should a virtual team leader do? How can employees and managers produce quality work under these circumstances? How can they prepare to cope in this remote team situation? These are the issues that this paper will address. Our research employs methods that combine logic, deduction and induction. The research's theoretical and methodological basis is determined by a systematic approach that allowed defining the precise scope of this paper by means of a literature review. Although over the last decades a considerable amount of research concerning virtual teams can be found, there are still significant gaps in our understanding, particularly in regard to remote work leadership. The paper analyzes the specific challenges faced by the remote employees. In order to manage the entire team efficiently, a leader needs to consider those challenges. Managers must be ready to start leading remote employees. Virtual teams and remote work are the future we all must get ready for.
\end{abstract}

KEYWORDS: challenge, leader, remote work, virtual team.

\section{INTRODUCTION}

Today, everyone has several devices that facilitate our smart lives: a laptop, a tablet, a smartphone, all backed up to the cloud. Our behavior has changed individually, while organizations have also shifted to smart, mobile organizations. Organizations are learning to transform a virtual workforce into a working virtual organization with productive teams that embrace the new circumstances, find fulfillment in their work while delivering results from a distance and across different time zones.

A virtual organization is built around the interconnectivity of people leveraging electronic networks, not a physical workplace. In these conditions, home office occurs naturally. Nowadays, employees are less tied to employers and for sure less tied to a certain desk office. Remote work has the disadvantage that both employees and managers could have worries about the lack of face-toface interaction. Managers could fear that employees will not perform well or efficiently enough. Employees, on the other hand, could encounter decreased access to managerial communication and support. Challenges can arise when distance becomes an issue, effectively meaning the organization has not adapted for inclusion and virtual work collaboration, and managers are not able to lead talent virtually.

\footnotetext{
*Corresponding author. E-mail address: corina.condea@uav.ro
} 
Leading a virtual team can be difficult, but also fulfilling. Overcoming the challenges means enjoying the reward of leading a united virtual team with all that this means: setting and reaching goals, pursuing and developing team members and then enjoying their laying into their strengths, to ultimately benefit from a strong, dynamic team that ensures that the best decisions are made and implemented.

The aim of the current paper is to provide a framework of what remote work and virtual teams mean, identify the challenges that remote work can face, those related to leading a virtual team leadership and propose solutions that a leader can adopt so that the interests of all parties involved will be achieved.

\section{REMOTE WORK AROUND THE WORLD}

The opportunity to work wherever you want with more flexible hours is a huge incentive for people. Remote work is fast becoming one of the most attractive benefits that an employer might provide. Working from outside the traditional office and having a work environment to choose from is now a key factor for many job seekers when assessing new career opportunities. Here are some interesting statistics on remote work that offer a clearer view.

In their "2020 State of Remote Work", Buffer and AngelList, stated that 98 percent of their respondents admitted that they would "like to work remotely, at least some of the time for the rest of their career”. The survey was conducted on over 3,500 remote workers from around the world, 57 percent of them full-time remote workers, who shared their experiences and thoughts of being a remote worker. Also, 97 percent of the respondents stated that "they would recommend remote work to others" (Buffer, n.d.).

OWLLabs in their "2018 Global State of Remote Work" analyzed the way employees around the world think about remote work. In order to collect the data for the study, they surveyed 3,028 remote and non-remote worldwide employees. Respondents encompassed 23 countries across six continents. The data show that 18 percent of the surveyed employees work remotely full-time and 21 percent of them work remotely more than one day per week. Also, 56 percent of the organizations represented by the respondents allow remote work, being "hybrid companies" or fully remote companies (OWLLabs, n.d.).

A special study conducted by FlexJobs and Global Workplace Analytics showed that there has been a major increase in the number of employees working remotely in the United States. Between the years 2005 to 2017, the growth in remote work was 159 percent. From 2016 to 2017 remote work grew 7.9 percent. In 2017, 4.7 million people from United States were working remotely, that was 3.4 percent of the United States population (Reynolds, 2019).

According to the Society for Human Resources Management, "SHRM Employee Benefits 2019", 27 percent of the respondents take advantage of full-time telecommuting as a flexible working benefit, compared to 22 percent in 2015. The study had the answers of the 2,763 survey participants across the United States (SHRM, n.d.).

Furthermore, in 2017, according to a survey of 1,001 people from United States who work full-time remotely from home, "75 percent of the respondents said they planned to work remotely for the rest of their career" and almost 81 percent of them said that they are satisfied at their current job. Plus, nearly 80 percent of respondents defined their average stress level as either "not stressed" or “moderately stressed" during the workweek (Amerisleep, n.d.).

According to the European Commission statistics data, in 2018, across the European Union, the total number of employees that worked every day or almost every day from home, from an external site, or while on the move and use various types of computers, portable devices or computerized equipment or machinery was 12 percent (Eurostat, 2018). 


\section{VIRTUAL TEAM MANAGEMENT}

Virtual team management is the capability to organize and coordinate effectively a territorially dispersed group whose members not only that are not in the same location, but they may not even have the same time zone (Powell et al., 2004). Teams should be characterized by mutual purpose, the right mix of skills and talent, open communication, clear roles, individual and collective performance, full participation, collective delivery of outputs, risk taking and trust. More briefly, a virtual or a remote team is a group of people who work independently for a common purpose across distance, time and organization (Hertel et al., 2004). The most specific characteristic of a virtual team is that, for a reason or another, the team members cannot meet face-to-face and because of that they rely on communication technologies (Morley et al., 2015). Remote team management needs a deeper understanding of individuals, processes and technologies, and awareness that trust is a more constrained factor compared to face-to-face interactions.

The implementation of virtual teams comes with benefits both for employers and employees, but also for the community. For organizations, virtual work provide lots of advantages. One of the main benefits is facilitating the access to the pool of talent that helps the employers' recruitment, but also the retention, of skilled labor. Another benefit is reducing costs. Remote work is one of the effective way of achieving operational savings. Working virtually from home excludes the need for an assign office, the time spent and the cost of transport to work. Remote work also cuts the travel expenses, business trips being replaced by web conferences. Virtual work supports organizations' decentralization and is reflecting the organization's flexibility and efficiency. For employees, remote work improves the work-life balance, enable time and money savings. Also, is has been observed an increased productivity that has positively impacted employees' motivation and job satisfaction. For community, virtual work creates employment opportunities for rural, isolated areas or poor developed countries. Also, the facility created by the virtual work has a major impact on the environment because it relieves traffic, reduce gas consumption and pollution, and improve air quality (Maher \& El Bedawy, 2015).

Nonetheless, virtual work and virtual teams represent the present and also the future. Remote work allows organizations to compete and to succeed in an increasingly globalized world, but adapting to the modern workforce and workplace is the real challenge. Once all challenges have been identified, a strong team can be built whose members are able to collaborate from all the corners of the world.

\section{CHALLENGES IN LEADING REMOTE EMPLOYEES OR TEAMS}

Remote teams give employers the chance to build an ideal team without boundaries. In theory, employees have the chance to reach the work-life balance. In reality, things are not that easy.

Managing a virtual team requires managers relying on the foundations of good management, that includes setting clear goals, running consistent meetings, communicating clearly and assessing team members' both individual and collective strengths (Shuffler et al., 2010).

Many people can manage a virtual team, but leading one is much different. What does a leader mean? "Someone whose actions inspire, empower and serve in order to elevate others over an extended period of time" (Eades, 2020).

There is a series of best practices that help ensuring that it's about leading and not just managing. However, there are several challenges that leaders encounter with remote employees, but there also are different solutions to solve these issues. The challenges pertain to communication, productivity, isolation and trust. Trust is the challenge that encompasses all others.

Leaders should focus on identifying the challenges that may affect their remote team members, and develop a solution plan in order to overcome them. 
Figure 1. schematically shows the challenges that remote workers face and the best practices that leaders can adopt in order to eliminate or reduce these challenges. The factors that might influence the implementation of these solutions are also mentioned.

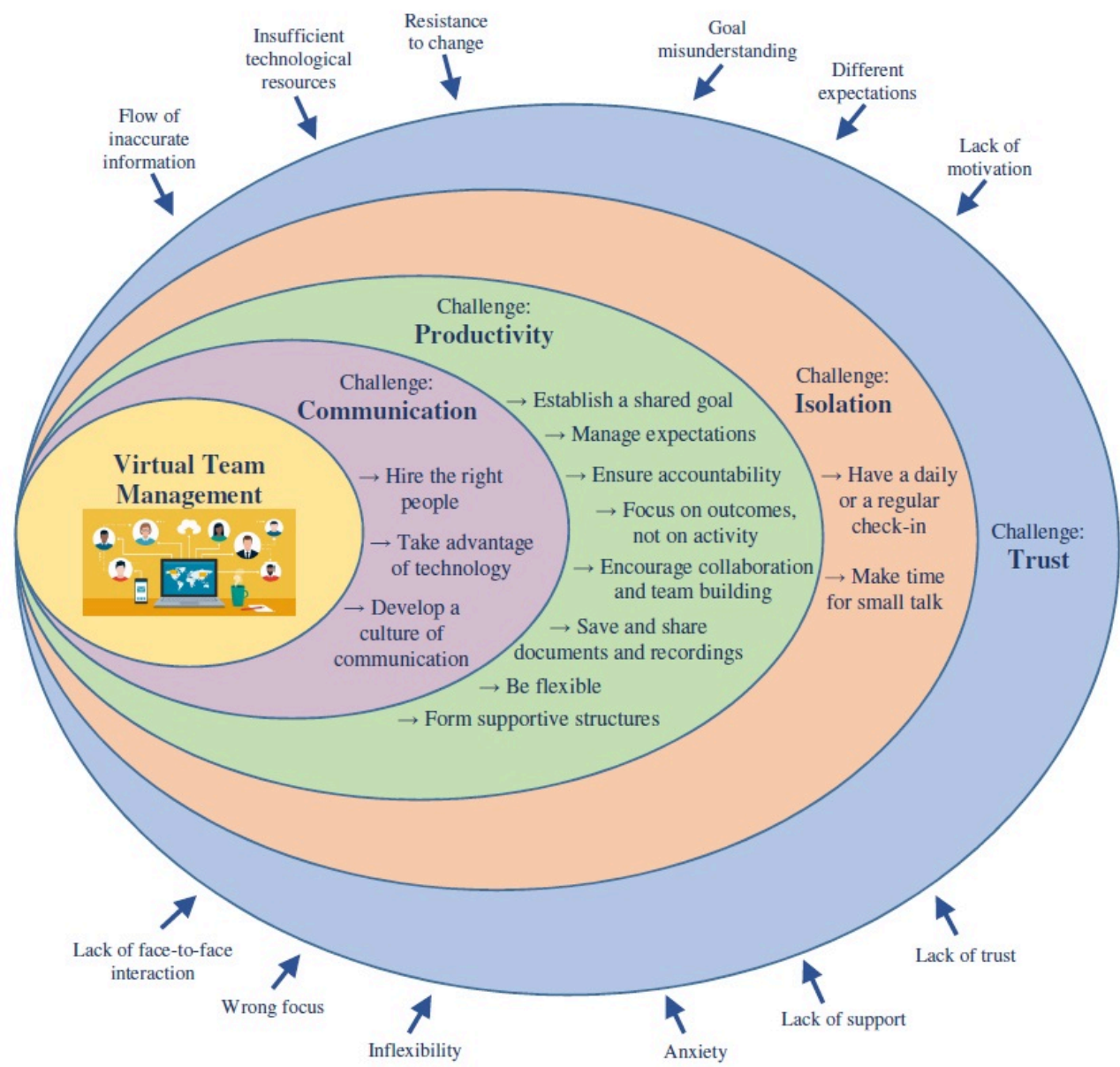

Figure 1. Challenges and best practices in leading virtual teams

Source: developed by the authors

\subsection{Challenge 1: Communication}

Communication is important in any workplace, but it is a significant challenge when managing remote workers especially because almost all the interactions occur via email, chat or calls. Ensuring a reliable flow of accurate information throughout the structure of the organization means recruiting the right people, using the right resources for the job and encouraging a communicative culture.

Best practices to encourage communication:

(a) Hire the right people

Hiring the right people starts with the interview process. The interview helps finding out how well someone communicates. Employees' communication abilities, especially if the employees work remotely full time, are a significant factor in virtual team performance.

(b) Take advantage of technology

Technology is what enables the existence of virtual teams. There are specific tools and software that facilitate remote work. Communication devices and tools like laptops, mobile devices, software or even a high-speed internet connection are a simple way of keeping everyone engaged. Ensure that the team has the resources they need to get the work done. Assuming that everybody has all those things is not reasonable, and is the manager's responsibility to make sure they do. It's important to 
provide training for employees to ensure that everyone is using tools consistently and to their fullest capacity and advantage.

(c) Develop a culture of communication

Fostering a culture of communication is the leader's responsibility. Developing communication strategies that resonate throughout the entire organization, including the virtual teams, can be challenging. Leaders must deliver clear, concise messages to their teams. Ambiguity must be removed by providing detailed guidelines that outline how team members are supposed to communicate. This is especially relevant when the team is culturally diverse and the members are located in different time zones. Also is important to lead by example. Knowing how to run an effective video team meeting is mandatory, because video calls are the platform for communication and connection that keeps everyone engaged and responsible. If employees see their leader as an effective communicator, they will follow by acquiring the good habits.

\subsection{Challenge 2: Productivity}

Productivity is at risk when employees work outside of a conventional office. Employees may not use their time efficiently and wisely in an environment without day to day supervision. On the other hand, due to a lack of boundaries, some employees risk burnout when they work remotely.

Best practices to boost productivity:

(a) Establish a shared goal

As a leader, communicating the expectations to the team, ensures team members that they are working toward a shared goal. Each team must have at least one goal, if not even several. Furthermore, it is vitally important that the team have a common understanding of how progress will be measured regarding reaching the shared goal or goals. A leader needs to ensure that everyone works toward the same goal and grant the necessary working hours into their job.

(b) Manage expectations

A leader helps the team to figure out what they have to do, and in this way, to create realistic expectations for their work. "Managing expectations" applies to the leader as well. It is mandatory to clearly state both the tasks and the reasons behind them, and to help the team understand correctly how the success is measured. That requires the definition of scope, deadlines and output for each task or project that the team is working on.

(c) Ensure accountability

The best way to ensure that everyone does their tasks is to set clear goals and expectations for each position and to have frequent check-ins to monitor progress. Expecting everyone to work at the same rate is unreasonable, but a manager should know how long tasks take to be done and also to know how much each employee accomplished every week, if not every day. Tracking the worked hours is particularly required when working for a client because the hours spent by working have to be invoiced. However, monitoring the worked hours offers a level of transparent accountability.

As a leader, the best place to start is always with yourself. A leader is the example that the team look to emulate. When is about remote work, a leader needs to have full confidence in employees' accountability, work ethic, and skills.

(d) Focus on outcomes, not on activity

Not every part of the work performed by a remote team can be controlled. A manager should not be trying to supervise every aspect of the team's work. Rather than concentrate on activity or count the hours worked, a leader should focus on the outcomes and evaluate the team accordingly. It is the results, not the hours, that matter. The team's achievements mean positive outcomes and revenues for the organization. Celebrating the successful results is a huge motivator for the employees. Employees who feel respected and appreciated will always do more than what is expected to be done. 
(e) Encourage collaboration and team building

Effective collaboration allows teams to connect and to develop trust as people get to know each other's behavior, way of thinking and working styles. First, is mandatory to have a clearly defined team. This sets the assumption that, even from a distance, people should be working together. Especially for the remote employees is necessary for them to know where they belong to and to whom they report to.

A leader must encourage teams to meet regularly through video conferencing, as these virtual faceto-face meetings help developing the sense of familiarity and community. Also, if possible, an effective action is to gather the whole team together, in person, once or twice a year. This is a perfect way to team-build. This offers the chance to remote employees to get to know each other outside their work positions.

(f) Save and share documents and recordings

Saving records and sharing documents are efficient actions and enhance collaboration and productivity. This implies recording the video calls for both, later reference and for those who missed the meeting to be able to catch up without having to rely on a colleague's understanding and interpretation.

(g) Be flexible

Managing a remote team requires reassessing what productivity really means. Punching the clock for eight hours is ruled out. Perhaps regular working hours are also out for many people. Working remotely does not mean that employees have to be bound to their desks from 8 AM to 5 PM. Instead, a leader must trust the team, the employees, and give them the flexibility and the freedom to do the work on the schedule that allows them be the most productive. When possible and necessary, flexibility on deadlines and having the right tools calm down the employees and help them get their work completed.

(h) Form supportive structures

A leader must make sure that all the team members receive the same attention. Without the clear features and limits that the office life provides, the go-getters of the team may overwork themselves until exhaustion and frustration. Employees should be encouraged to keep regular working hours and to benefit of their paid time off.

Also, leaders should be focused on being good listeners and providing the appropriate support to each of the remote team members.

Having an informal group that may be voluntarily accessed by the remote team members keeps them connected and more responsible for the ongoing projects and for their daily tasks.

\subsection{Challenge 3: Isolation}

One of the toughest things about working from home, particularly for those that are used to work in an office environment, is the sense of loneliness that can set in. Compared to onsite employees, remote employees are more likely to feel isolated, stressed or disconnected. Being around others and socializing are essential for humans' evolution, but are also factors that influence psychological and physical health.

These communication issues are a concern for leaders. Is the leader's responsibility to engage socially the team members and to encourage them to spend time out of the house.

Best practices to avoid isolation:

(a) Have a daily or a regular check-in

Remote managers should be in a regular communication with their team and should establish a daily call or virtual hangouts such as morning coffee or lunch with their remote employees. This should be visual through a video call. The team need to see their leader and the leader need to see the team. The daily check-in could take the form of a series of one-on-one calls, if employees work more independently from each other, or a team call, if employees' work requires collaboration. The 
purpose is simple: to set the agenda, to provide the resources and the feedback that the team members need and to ensure employees that they have all their leader's support.

(b) Make time for small talk.

A leader should build a relationship with every member the team. The relationship does not build up from talking strictly about work. The relationship comes from being able to get to know the employee as a whole person. A little information about family, living place, personal aspirations demonstrate caring which is important for the leader to understand employees' motivations. Taking the time to getting to know all this will also make employees more engaged.

\subsection{Challenge 4: Trust}

Trust is the key in every relationship. It is easier to lose the trust than to build it. When employees have confidence into each other and their manager, and believe they work toward a shared goal and vision, the teamwork, cooperation and engagement occur naturally. Trust is the most difficult element needed to strengthen a team and is mandatory for the future of the team. This is why it is critical to lead with positivity, purpose and proactivity, while also being empathetic and compassionate. It is hard to achieve all these in an environment where face-to-face interaction is uncommon.

In a virtual environment, trust depends and is based more on the capacity to deliver the task than on interpersonal relationships. Members of the remote teams have to be sure that their colleagues will perform their obligations with competence, integrity and will act appropriately, consistently and predictably, while being respectful for each other's well-being.

\section{CONCLUSIONS}

Our study discusses and illustrates the challenges associated with virtual team leadership. We focused on four major challenges leaders are confronted with when they manage remote work. Based on our approach and the discussed challenges, we highlighted several solutions for a successful and sustainable leadership of virtual employees or teams, developing a theoretical model of best practices in leading remote teams.

Remote work means more than just the technology advancement, it helps the way we work, manage and lead. Each leader has his own particularities. Each employee is unique. Every business is different. There is not one right way to best lead remote employees. Create the environment, practices and expectations that suit the team best. Organizations and leaders that are digitally ready seek to create the best adapted to technology workplaces and help their employees in achieving the organization's goals.

Leaders need to consider and address the factors that make remote work particularly demanding. To this end, we identified four key challenges: communication, productivity, isolation, and trust. By applying the proposed solutions to each of the aforementioned challenges leaders can establish practices that enable them to better work with the virtual team. Having the support of their leader, employees may feel encouraged to develop their own pattern for achieving the work-life balance. As was noted by one virtual team leader, "I must be a diplomat to help teams overcome cultural differences, an ambassador to keep sponsors around the world updated on the team's progress, a psychologist to provide a variety of rewards to a diverse and often isolated group of team members, an executive, a coach, and a role model all at the same time.” (Hellriegel \& Slocum, 2009).

What we think determines what we see and do and how good we lead. Our mentality restricts or opens us up to change and adaptation. In terms of remote work and virtual teams, the need to adapt leadership practices is imperative. In the years to come, a greater organizational effort to train potential virtual team leaders must be expected. The organizations that understand the importance 
of virtual team leadership development are likely to see major benefits from their efforts and investments.

Managing remote teams has a lot in common with managing teams on-site. Nonetheless, assuming that a remote employee is the same as one who works in an office together with other colleagues is a mistake. And so, challenges related to virtual team management can arise. Determining and implementing solutions for these particular challenges is an achievement not only for the team, but also for the leader. The better a leader understands the needs and challenges of remote employees, the better the leader becomes and the better prepared he is for a world where remote work and virtual teams are quickly becoming the norm.

\section{REFERENCES}

Remote workers and rest. Amerisleep. (n.d.). In Amerisleep. Retrieved July 9, 2020, from https://amerisleep.com/blog/remote-workers-and-rest/.

The 2020 State of remote work. Buffer. (n.d.). In Buffer. Retrieved July 10, 2020, from https://lp.buffer.com/state-of-remote-work-2020.

Eades, J. (2020). Building the best: 8 proven leadership principles to elevate others to success. New York: McGraw-Hill.

Hellriegel, D. \& Slocum, J. W. (2009). Organizational Behavior. Mason: South-Western Cengage Learning.

Hertel, G., Konradt, U. \& Orlikowski, B. (2004). Managing distance by interdependence: Goal settings, task interdependence, and team-based rewards in virtual teams. European Journal of Work and Organizational Psychology, 13 (1), 1-18.

Eurostat. (2018). ICT usage at work - Work from home, from an external site or on the move. Retrieved July 12, 2020, from https://appsso.eurostat.ec.europa.eu/nui/submitViewTableAction.do.

Reynolds, B. W. (2019). 159\% Increase in remote work since 2005: FlexJobs \& Global Workplace Analytics Report. Retrieved July 9, 2020, from https://www.flexjobs.com/blog/post/flexjobsgwa-report-remote-growth/.

Maher, A. \& El Bedawy, R., (2015). Core Practices for Managing Virtual Employees in Public Organizations. Journal of Business and Economics, 6 (1), 113-120.

Morley, S., Cormican, K. \& Folan, P. (2015). An analysis of virtual team characteristics: A model for virtual project managers. Journal of Technology Management \& Innovation, 10 (1), 188203.

2018 Global state of remote work. OWLLabs (n.d.). In OWLLabs. Retrieved July 12, 2020, from https://www.owllabs.com/state-of-remote-work/2018.

Powell, A., Piccoli, G. \& Ives, B. (2004). Virtual teams: A review of current literature and directions for future research. The DATA BASE for Advances in Information Systems, 35 (1), 636.

Shuffler, M. L., Wiese, C. W., Salas, E. \& Burke, C. S. (2010). Leading one another across time and space: Exploring shared leadership functions in virtual teams. Revista de Psicología del Trabajo y de las Organizaciones, 26 (1), 3-17.

2019 Employee benefits. SHRM (n.d.). In SHRM. Retrieved July 10, 2020, from https://www.shrm.org/hr-today/trends-and-forecasting/research-andsurveys/pages/benefits19.aspx. 